\title{
The concept of a unified geoinformational space of the region: ecological aspect
}

\author{
Imran Akperov ${ }^{1}$ and Vladimir Khramov ${ }^{1, *}$ \\ ${ }^{1}$ PEI HE SU (IMBL), 344068, Nagibina Ave., 33a/47, Rostov-on-Don, Russia
}

\begin{abstract}
The principles of describing a single information space as a key component of the substance-energy-information triad as applied to a geographically limited area are considered. An open structure of the knowledge base is proposed, which provides storage and development of a multidimensional model of this geoinformation space based on the study of the connectivity and semantic interoperability of measurable components. An approach to modeling the intellectual space of the region as one of the layers of a single geoinformation space is proposed.
\end{abstract}

\section{Introduction}

There are many definitions of the information space, primarily related to the results of the semantic activity of mankind. As a rule, it is assumed $[1,2]$ that "its main components are information resources, means of information interaction and information infrastructure" [3]. The authors, in their studies [4-13], would like to emphasize that, agreeing generally with this approach, it is necessary to point to the well-known synergetic paradigm, which involves the description of the world around us by three interrelated components: matter, energy, information [13].

The main purpose of the study presented in this article was to develop a methodology that allows, from the point of view of a single information space, to assess the level of ecology in the regions of the region on the basis of heterogeneous indicators set by time series, to rank the regions based on the constructed soft estimates, and then to aggregate the estimates of the regions into a comprehensive assessment of the environmental (including information and environmental) safety of the entire region. To achieve this goal, the following tasks have been set and solved [9].

1. To analyze existing methods and models for assessing the ecological state of the region.

2. To develop a universal fuzzy-multiple methodology based on standard five-level $[0,1]$ classifiers, allowing to give numerical assessments of the ecological safety of the regions of the region on the basis of time series of dissimilar indicators, as well as to rank them based on the constructed estimates.

3. To create a methodology for the formation of a comprehensive assessment of the social sustainability of agricultural production in the region based on the corresponding assessments of its regions.

4. To form a database of indicators characterizing the state of ecology and nature management in the regions of the Rostov region based on open Internet sources.

* Corresponding author: vxpamov@inbox 
5. To test the developed methodology for assessing the environmental safety of 43 districts of the Rostov region, compiling their rating based on the constructed assessments and forming a comprehensive assessment of environmental safety in the Rostov region.

The study of literary sources allows us to conclude that the existing models are focused on solving the problems of specific research and do not have universality, which makes it possible to bring together the obtained estimates of various subsystems, rank the areas based on the constructed estimates, and then aggregate them into a comprehensive assessment of the environmental safety of the entire region.

Study of 43 districts of the Rostov region to assess the level of environmental safety. The results of the ranking by districts of Rostov showed that the most favorable ecological situation is observed in three districts of the Rostov region: Ust-Donetsk, Remontnensky and Tsimlyansky districts (belonging to the G2 term - "high level of environmental safety"). 38 districts belong to the G3 term - "medium level of environmental safety". One district, Matveyevo-Kurgan, belongs to the G4 term - "low level of environmental safety". There are no districts that belong to the extreme terms G1 - "very high level of environmental safety" and G5 - "very low level of environmental safety". The analysis of the share contribution of each of the terms is shown in the diagram (Fig. 1). The described analysis was carried out for each of the five groups of indicators.

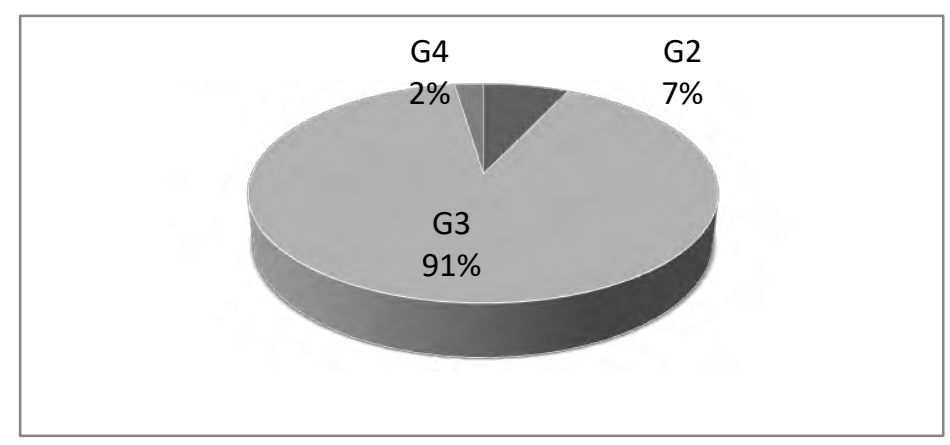

Fig. 1. Analysis of the share of terms from the total number of districts of the Rostov region

The task of the analysis is to build a rating of districts and determine the factors that determine the lag of some districts in front of others, and, therefore, to isolate the directions in which management activities should be conducted aimed at leveling the level of environmental safety in the entire region. Thus, the priority objects of further analysis are the districts completing the rating, first of all - Matveyevo-Kurgan district. The low rating of this area is due to the low ratings (term $\left.\mathrm{G}_{5}\right)$ on the fourth and fifth sets of indicators $\left(g_{4}=\right.$ "assessment of the share of protected natural areas (district)", $g_{5}=$ "the level of financing of environmental protection measures (district)"). In addition, the second indicator related to the term leaves much to be desired $\mathrm{G}_{4}$ ( $g_{2}=$ "assessment of water pollution (district)"). Thus, in order to improve the environmental situation in this area, it is necessary, first of all, to attract funds for the organization of environmental activities in the MatveyevoKurgan area. It is also desirable to organize nature reserves and other specially protected areas on its territory, as well as to attract attention and consult with specialists on the organization of the correct environmentally friendly use of water resources in this area.

\section{Calculation of the final assessment of environmental safety in the Rostov region}


Based on the constructed assessments, the final assessment of environmental safety in the entire region was calculated. The standard five-level [0,1] classifiers were used as a mathematical tool, and the share of the area of each of the districts in the total area of the Rostov region was used as the weighting coefficients of the districts. It was found that the final grade: $g$ (Rostov region) = "comprehensive assessment of the level of environmental safety in the Rostov region" $=0,523$, which corresponds to the term $\mathrm{G}_{3}$ - "average level of environmental safety".

\section{Features of accounting for the eco-information component in the regions}

At present, not enough attention has been paid to the meaningful nature of the relationship between various approaches to determining the amount of information, and a satisfactory answer has not been given to the question of how to highlight and optimally parameterize information and environmental indicators of comfort and safety, the quality of the information system.

For the choice and rational distribution between the specified forms of adequacy of the entire set of measures of the amount of information [10], from the point of view of a task that is important in the aspect of information ecology, one should decide on the actual environmental (eco-information) parameters and restrictions, according to which we will conduct the required quantitative and qualitative assessments.

To solve this problem, based on the laws of information ecology [11, 12], it is necessary to take as a basis a possible strategy for designating the opposite boundaries of the ecological limit threshold levels of the quantity and quality of information, subject to which the well-being and safety of the human intellectual and psychological system is preserved.

Let's designate these environmental threshold levels separately for each (syntactic, semantic and pragmatic) measures.

We believe that in the case of solving the subtask of building an information-protected ecosystem, in order to form a rating scale in the pair "restriction - freedom" of information, it is most rational to use information measure Lovtsov - Knyazev $\boldsymbol{H}_{\mathbf{L K}}[13,14]$.

The rational distribution between the above forms of the adequacy of appropriate mathematical measures for the presentation of information is given in table. 1 .

Table 1. Distribution of mathematical measures in the information system

\begin{tabular}{|c|c|c|}
\hline Form & Index & Measure of information \\
\hline Syntactic & $\begin{array}{c}\text { a) the degree of reduction } \\
\text { uncertainties } \\
\text { b) the minimum amount of } \\
\text { information }\end{array}$ & $\begin{array}{c}\text { a) } \mathrm{H}_{\mathrm{S}}\left(\mathrm{p}_{\mathrm{m}}, \mathrm{N}\right)-\text { Shannon } \\
\mathrm{H}_{\mathrm{H}}(\mathrm{N})-\text { Hartley } \\
\text { b) } \mathrm{Kf}(\mathrm{s})-\text { Kolmogorov }\end{array}$ \\
\hline Semantic & $\begin{array}{c}\text { combinatorial measure of the diversity } \\
\text { of a system-wide thesaurus }\end{array}$ & $\mathrm{H}_{\amalg}(\mathrm{m}, \mathrm{T})-$ Schrader \\
\hline Pragmatic & $\begin{array}{c}\text { a) a probabilistic measure of the } \\
\text { appropriateness of management } \\
\text { b) measure of information protection }\end{array}$ & $\begin{array}{c}\text { a) } \mathrm{I}_{\mathrm{X}}\left(\mathrm{P}_{\mathrm{G}}\right)-\text { Kharkevich } \\
\text { b) } \mathrm{H}_{\mathrm{LK}}\{(\mathrm{p}) \delta(\mathrm{x})\} \text { Lovtsov - } \\
\mathrm{Knyazev}\end{array}$ \\
\hline
\end{tabular}

\section{Summary assessment of quantitative and qualitative environmental thresholds using Veitch - Karnot squares}


To solve the problem of a consolidated assessment of the ecological threshold quantitative and qualitative levels of information, it is proposed to use the well-known Veitch-Carnot squares [15], which represent tables from a set of control actions. So, for three qualitative levels of information: syntactic (I); semantic (M); pragmatic ( $\Psi)$, ensuring the equivalence of information interactions, the Veitch - Karnot squares will have the following form (fig. 2).

\begin{tabular}{|l|l|l|l|l|}
\hline \multicolumn{2}{|l|}{} & \multicolumn{2}{l|}{} \\
\hline $\mathrm{M}$ & $\overline{\mathrm{I}} \mathrm{M} \Psi^{1}$ & $\mathrm{I} \mathrm{M} \Psi^{2}$ & $\overline{\mathrm{I}} \mathrm{M} \Psi^{3}$ & $\overline{\mathrm{I}} \mathrm{M} \bar{\Psi}^{4}$ \\
\hline$\overline{\mathrm{M}}$ & $\overline{\mathrm{I}} \overline{\mathrm{M}} \Psi^{5}$ & $\overline{\mathrm{I} M} \Psi^{6}$ & $\overline{\mathrm{I}} \overline{\mathrm{M}} \Psi^{7}$ & $\overline{\mathrm{I}} \overline{\mathrm{M}} \bar{\Psi}^{8}$ \\
\hline & $\bar{\Psi}$ & & & $\bar{\Psi}$ \\
\hline
\end{tabular}

Fig. 2. Veitch - Karnot table

Squares arranged in rows $\mathrm{I}, \mathrm{M}, \Psi$, contain the corresponding component in this set. Cells containing $\overline{\mathrm{I}}, \overline{\mathrm{M}}, \bar{\Psi}$, characterized by the absence of the corresponding component in this set. Each set is considered interrelated with the rest of the sets. The transition from one information state, characterized by a set of the above environmental parameters, to another (for example, $\overline{\mathrm{I}}, \overline{\mathrm{M}}, \bar{\Psi} \rightarrow \mathrm{I} M \Psi$ ) is performed based on the analysis of the severity of these properties in the information system and, as a consequence, the use of control actions.

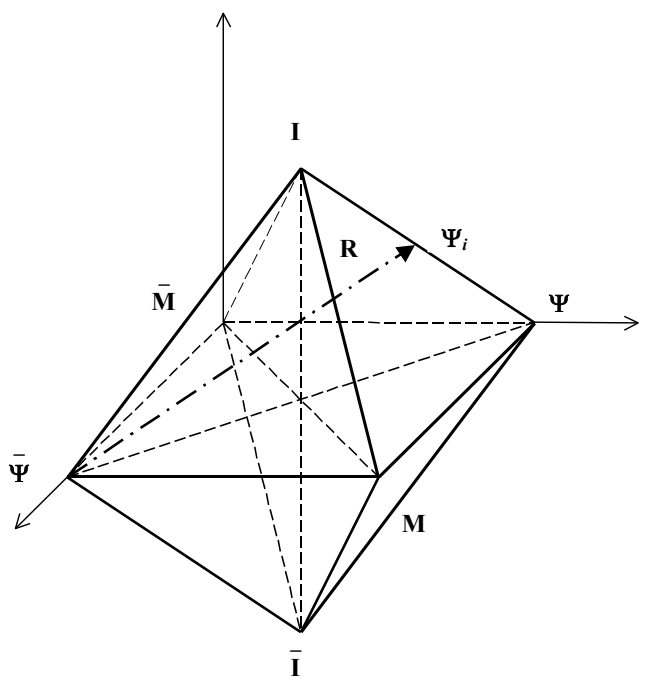

Fig. 3. Three-component model of ecological levels of information quality

In view of the difficulty of implementation, the transition occurs not along the shortest path, but through a certain sequence of states. For clarity, the Veitch table in our case can be represented as a three-component model of environmental information parameters on an octahedron (Fig. 3). The figure shows that the transition of their plane of insufficient 
manifestation of properties ( $\overline{\mathrm{I}} \overline{\mathrm{M}} \bar{\Psi}$ ) to the desired (I M $\Psi$ ) it is advisable to execute, bypassing the vertices of the octahedron.

Triangles $\overline{\mathrm{I}} \overline{\mathrm{M}} \bar{\Psi}, \overline{\mathrm{I}} \overline{\mathrm{M}} \Psi, \overline{\mathrm{I}}_{\mathrm{M}} \bar{\Psi}, \overline{\mathrm{I}}_{\mathrm{M} \Psi, \mathrm{I}} \overline{\mathrm{M}} \bar{\Psi}, \overline{\mathrm{M}}_{\Psi}, \mathrm{IM} \bar{\Psi}_{\text {, IM } \Psi \text { correspond }}$ to Veitch squares, while the vertices of the tetrahedron can be coded as follows (Table 2).

Table 2

\begin{tabular}{|c|c|c|c|c|}
\hline & I & $\mathbf{M}$ & $\Psi$ & Dividing plane \\
\hline$\overline{\mathrm{I}}$ & $\begin{array}{l}1 \\
-1\end{array}$ & $\begin{array}{l}0 \\
0\end{array}$ & $\begin{array}{l}0 \\
0\end{array}$ & $\mathrm{M} \Psi \overline{\mathrm{M}} \bar{\Psi}$ \\
\hline$\frac{\mathrm{M}}{\mathrm{M}}$ & $\begin{array}{l}0 \\
0\end{array}$ & $\begin{array}{l}1 \\
-1\end{array}$ & $\begin{array}{l}0 \\
0\end{array}$ & I $\Psi \overline{\mathrm{I}} \bar{\Psi}$ \\
\hline$\Psi$ & $\begin{array}{l}0 \\
0\end{array}$ & $\begin{array}{l}0 \\
0\end{array}$ & $\begin{array}{l}1 \\
-1\end{array}$ & $\mathrm{I}_{\mathrm{M}} \overline{\mathrm{I}} \overline{\mathrm{M}}$ \\
\hline
\end{tabular}

It should be noted that the determination of finding a separate eco-informational parameter at a given moment on a specific field of the Veitch square [16] and the need to apply the appropriate methodology for assessing the quality of information are currently based on the expert method. Fuzziness in the expert assessment can be represented using the apparatus of the theory of fuzzy sets by introducing the membership function $\mu_{A}$ (I, M, $\Psi)$. Fuzzy@ set $A$ is defined as a collection of ordered pairs made up of elements $x_{\mathrm{I}}, x_{\mathrm{M}}, x_{\Psi}$ and the corresponding degrees of belonging $\mu_{A}(x)$. This means that the transition from the complete non-belonging of the state of the system to the set of the above-mentioned ecoinformational parameters to its complete belonging occurs not abruptly, but smoothly, gradually, and the belonging is expressed by a number from the interval $[0,1]$ " [17]. For a fuzzy set $A$, the membership function takes the following form:

$$
\mu_{A}(x)=\left(\mu_{\mathrm{I}} \wedge \mu_{\mathrm{M}} \wedge \mu_{\Psi}\right)(x)=\min \left\{\mu\left(x_{\mathrm{I}}\right), \mu\left(x_{\mathrm{M}}\right), \mu\left(x_{\Psi}\right)\right\}
$$

for any $\mathrm{x}$ from the universal set.

Transitions $\overline{\mathrm{I}} \rightarrow \mathrm{I}, \overline{\mathrm{M}} \rightarrow \mathrm{M}, \bar{\Psi} \rightarrow \Psi$ are calculated as transitions to complements of the corresponding fuzzy sets:

$$
\begin{aligned}
& \mu_{\mathrm{I}^{\prime}}=1-\mu_{\mathrm{I}} ; \\
& \mu_{\mathrm{M}^{\prime}}=1-\mu_{\mathrm{M}} ; \\
& \mu_{\Psi^{\prime}}=1-\mu_{\Psi} .
\end{aligned}
$$

\section{Conclusions}

The proposed methodology for assessing the ecological well-being in the region, in comparison with traditional methods, has a number of new important advantages, such as: 1) versatility due to the presence of a single algorithm for working with time series of these heterogeneous indicators to aggregate them into the final assessment; 2) variability, due to changes in the complexes of parameters, as well as weighting coefficients without significant complication of 
the models in accordance with the research objectives and the requirements of experts; 3) simplicity of software implementation; 4) the presence of a transparent scheme that allows you to trace the process of forming estimates and select indicators leading to a decrease.

\section{References}

1. Y. Setyanto, P.T. Anggarina, P. Sundoro, Public Relations in University: Managing Internal Communication. Conference: Proceedings of the 1st Padjadjaran Communication Conference Series, PCCS 2019 (Bandung, West Java, Indonesia, 2019) DOI: 10.4108/eai.9-10-2019.2291111.

2. Ó.G. Agustín, Sociology of Discourse. From institutions to social change (2015) URL: https://www.researchgate.net/publication/294428394_Sociology_of_Discourse_From_i nstitutions_to_social_change (Last accessed 10.04.2020)

3. V. Terziev, The Good Practices in the Regulation of Social Development. SSRN Electronic Journal 5(14), 568-578 (2019) DOI: 10.2139/ssrn.3411520

4. G.I. Akperov, V.V. Khramov, A.A. Gorbacheva, Using Soft Computing Methods for the Functional Benchmarking of an Intelligent Workplace in an Educational Establishment: Advances in Intelligent Systems and Computing 1095, 54-60 (2020)

5. G.I. Akperov, V.V. Khramov. A Fuzzy Semantic Data Triangulation Method Used in the Formation of Economic Clusters in Southern Russia .-Advances in Intelligent Systems and Computing 1095, 340-344 (2020) DOI: 10.1007/978-3-030-35249-3_43

6. I.G. Akperov V.V. Khramov, V.I. Lukashevitsh, O.Yu. Mityasova, Fuzzy Methods and Algorithms in Data Mining and Formation of Digital Plan-schemes in Earth Remote Sensing.: Procedia Computer Science 120-125 (2017). DOI: 10.1016/j.procs.2017.11.218

7. I.G. Akperov, G.I. Akperov., V.V. Khramov, et al., Soft Models of Management in Terms of Digital Transformation Monograph, Rostov-on-Don (2019)

8. I.G. Akperov, V.V. Khramov, Development of Instruments of Fuzzy Identification of Extended Objects Based on the Results of Satellite Monitoring. Advances in Intelligent Systems and Computing 896, 325-332 (2019) DOI: 10.1007/978-3-030-04164-9_44

9. L.V. Sakharova, M.B. Stryukov., G.I. Akperov, Optimization of Agricultural Land use on the Basis of Mathematical Methods of Financial Analysis and the Theory of fuzzy Sets: Advances in Intelligent Systems and Computing 896, 790-798 (2019) doi.org/10.1007/978-3-030-04164-9_104

10. S.O. Kramarov, A.R. Groshev, V.V. Khramov, A.V. Belyaev, Development of a New Method of Management of Ergo-Technical System on the Basis of ITS Dynamics Monitoring: IOP Conference Series: Materials Science and Engineering. Collection of materials of the XV International Scientific - Technical Conference Don State Technical University 012038 (2019) DOI.10.1088/1757-899X/680/1/012038

11. S.O. Kramarov, V.A. Bezuevskaya , V.V. Khramov, The Possibility of Artificial Intelligence in the Development of the Third Mission of Universities. 2nd International Conference on Robotics and Artificial Intelligence, ICRAI 2019 58-60 (2019)

12. S.O. Kramarov, V.V. Khramov, Methodology of Formation of Unite GeoInformational Space in the Region Communications in Computer and Information Science, 1201 CCIS 309-316 (2020) DOI: 10.1007/978-3-030-46895-8_24 
13. S.O. Kramarov, V.V. Khramov., I.O. Temkin, The principles of Formation of United Geo-informational Space Based on Fuzzy Triangulation: Procedia Computer Science 835-843 (2017) DOI: 10.1016/j.procs.2017.11.315

14. J.H. Choi, The Substantive Canons of Tax Law. Stanford Law Review 72, 195 (2020) URL:https://www.researchgate.net/publication/341910630 The Substantive_Canons of Tax Law (Last accessed 10.04.2020)

15. E.A. Arapova, G.I. Lukyanova, L.V. Sakharova, G.I. Akperov, Fuzzy-logic Analysis of theLevel of Comfort and Environmental Well-being of the Urban Environment on the Example of Large Cities of Rostov Region. Advances in Intelligent Systems and Computing 896, 643-650 (2019) DOI: 10.1007/978-3-030-04164-9_84

16. A.S.A. Razzaq, L. Swidi, On classification of fuzzy set theory. Conference: on classification of fuzzy set theory (2020) URL: https://www.researchgate.net/publication/343682945_on_classification_of_fuzzy_set_t heory (Last accessed 10.04.2020)

17. A. Ziyyat, H. Magrez, K. Salmi, A Novel Expert Evaluation Methodology Based on Fuzzy Logic. International Journal of Emerging Technologies in Learning (iJET) 14(11), 160 (2019) DOI:10.3991/ijet.v14i11.10280 